\title{
Em defesa do sistema único de saúde: discursos de vereadores, conselheiros e profissionais de saúde
}

\section{In defense of unified health system: discourses of health professionals, municipal counselors and aldermen}

\author{
Karly Garcia Delamuta ${ }^{1}$; Flaviana Alves Dias²; Marisa Silva3; Célia Regina \\ Rodrigues Gil ${ }^{4}$
}

\begin{abstract}
Resumo
O objetivo deste estudo foi avaliar as percepções de conselheiros municipais de saúde, profissionais da atenção primária e vereadores sobre o Sistema Único de Saúde e a Política Nacional da Atenção Básica. A partir destes, pretende-se analisar seu envolvimento para melhoria do sistema e verificar a participação em projetos que fomentem discussões sobre os desafios desta temática. A investigação teve abordagem qualitativa, sendo os dados coletados por meio de 28 entrevistas semiestruturadas realizadas entre novembro e dezembro de 2010, no município de Londrina-PR. Entre os grupos entrevistados fica evidente maior aproximação conceitual dos profissionais de saúde, quanto as políticas de saúde pública. Entretanto, todos demonstram equívocos e distância quanto aos princípios e diretrizes do Sistema Único de Saúde, bem como das disposições da Política Nacional de Atenção Básica. As considerações apontadas indicam foco na doença, priorização das consultas médicas e maior valorização das estruturas hospitalares. Ainda que conceituada com equívocos, são percebidas limitações nos serviços de saúde pública. Contudo, as proposições para mudança do quadro permanecem com conotações distorcidas. Nestes grupos não foram encontrados projetos ou ações práticas para melhoria do cenário da saúde pública. Conclui-se a necessidade de apropriação de conhecimento teórico sobre as políticas que envolvem a organização da saúde, pelos atores, para que sejam mudados os paradigmas do modelo tradicional e, a atenção básica seja valorizada e compreendida como forma de organização do sistema.
\end{abstract}

Palavras-chave: Sistema Único de Saúde. Atenção primária em saúde. Participação popular. Recursos humanos em saúde. Políticas públicas de saúde.

\begin{abstract}
The objective of this study was to evaluate the perceptions of municipal health counselors, primary care professionals and aldermen about the Unified Health System and the Brazilian Primary Care Policy. From these, we intend to analyze their involvement to improve the system and verify participation in projects that foster discussions about the challenges of this issue. The investigation took a qualitative approach, the data being collected through 28 semi-structured interviews conducted between November and December 2010 in Londrina-PR. Between the interviewed groups, it becomes apparent that health professionals have better conceptual approach of public health policies. However, all groups demonstrate
\end{abstract}

${ }^{1}$ Graduada em Enfermagem, Residente em Saúde da Família, Universidade Estadual de Londrina (UEL), Londrina-PR.

${ }^{2}$ Graduada em odontologia pela Universidade Estadual de Londrina. Pós-graduada em Saúde da Família pela Residência Multiprofissional em Saúde da Família, Universidade Estadual de Londrina (UEL), Londrina-PR.

${ }^{3}$ Graduada em Psicologia pela Universidade Estadual Paulista Júlio de Mesquita Filho UNESP / Campus Assis; pós graduações em Especialização em Gestão em Saúde (2014) pela Universidade Federal de São Paulo - UNIFESP e Residência Multiprofissional em Saúde da Família (2011), Universidade Estadual de Londrina (UEL), Londrina-PR.

${ }^{4}$ Graduada em Enfermagem e Obstetrícia pela Universidade Estadual de Londrina, Mestre em Saúde Coletiva pela Universidade Estadual de Londrina e Doutora em Saúde Pública pela Fundação Oswaldo Cruz/Escola Nacional de Saúde Pública. Professora Associada do Departamento de Saúde Coletiva, Universidade Estadual de Londrina (UEL), Londrina-PR. 
misconceptions and distance for the principles and guidelines of the Unified Health System, as well as provisions of the Brazilian Primary Care Policy. The findings pointed indicate focus on disease, prioritization of medical consultations and greater value of hospital structures. Although conceptualized with misconceptions, limitations are noted at the public health services. However, the proposals to change the frame remain with distorted connotations. In these groups no practical actions or projects were found to improve the public health scenario. It is concluded the need for ownership of theoretical knowledge about policies involving health organization, by stakeholders, to change the paradigms of the traditional model to the Primary Health care become valued and understood as form of organization of the system.

Keywords: Unified health system. Primary health care. Community participation. Health manpower. Public health policies.

\section{Introdução}

O Sistema Único de Saúde (SUS) “é um arranjo organizacional" do Estado brasileiro que busca através de articulações entre serviços e iniciativas, tanto públicas quanto privadas, a consolidação da política de saúde procurando traduzir em ações seus princípios e diretrizes. Assim, estes firmam a base para a constituição da reorganização do sistema em suas proposições formativas, concernentes aos serviços e práticas de saúde (VASCONCELOS; PASCHE, 2006).

A luta pela construção do SUS mistura-se à própria história política e social do Brasil. Inspirado na democratização da sociedade, o SUS, embora represente um exemplo de conquistas no campo das políticas públicas ainda não se constitui efetivamente como política de Nação, haja vista a falta de mecanismos estruturantes de financiamento, entre outros, com o qual se confronta desde sua criação (GIL, 2006).

Os avanços efetivos dessa organização estão intimamente ligados a outros aspectos relevantes para a sua consolidação, como o adequado aporte de recursos financeiros; o fortalecimento da capacidade gestora nos três níveis de governo e; a permeabilidade das instituições do setor saúde aos valores democráticos; aporte legislativo e fortalecimento do controle social (LEVCOVITZ; LIMA; MACHADO, 2001).

No período da ditadura militar a política econômica não priorizava a área da saúde. Neste contexto é que nasce e se organiza o movimento sanitário em defesa da democratização da saúde, principalmente para as camadas sociais excluídas do acesso aos serviços de saúde (NEGRI; VIANA, 2002). O movimento sanitário com pensamento contra hegemônico, aglutinou pessoas em reuniões, seminários e encontros, onde foram delineando as propostas para o Sistema Nacional de Saúde com intuito de politizar a questão da saúde e dar visibilidade aos problemas da população brasileira (ESCOREL, 1998).

Em 1986, a VIII Conferência Nacional de Saúde (CNS) reuniu aproximadamente cinco mil pessoas entre profissionais, prestadores de serviços e usuários para discutir as diretrizes políticas setoriais. Nesta Conferência, foi aprovada a Unificação do Sistema de Saúde e definidas propostas relativas ao conceito ampliado de saúde, ao direito a cidadania, dever do Estado e ao financiamento do sistema (ESCOREL, 1998).

Esse intenso processo social promoveu a Constituição Federal de 1988 que continha, como afirma Guedes (2001), as mais amplas garantias democráticas e sociais já expressas num texto constitucional brasileiro culminando com a inovadora estruturação da Seguridade Social (Saúde, Previdência e Assistência Social) e a compreensão da saúde como "Direito de Todos e Dever do Estado".

Frente à necessidade de fortalecer o processo normativo do SUS, em fevereiro de 2006 foi 
firmado o Pacto pela Saúde, que nas suas três dimensões - Pacto pela Vida, em Defesa do SUS e de Gestão - delibera sobre as responsabilidades das esferas de governo gestoras do SUS. Para além das averbações acertadas com o Pacto, é importante ressaltar que se trata de um elemento gestor inovador, pela preocupação em contemplar os princípios do SUS assegurando seu financiamento de forma mais integral, respeitando a diversidade do Brasil, incentivando a repolitização da saúde e, a mobilização social e institucional em defesa do SUS (BRASIL, 2006a).

Nos últimos anos evidencia-se uma fragilidade no setor público, principalmente relacionada à dificuldade de se fazer valer os direitos sociais constitucionalmente garantidos e a efetiva capacidade de oferta dos serviços públicos garantindo a acessibilidade. Nesse sentido, com a finalidade de assegurar a continuidade destas conquistas sociais, a firmação do Pacto pela Saúde, principalmente na composição da diretriz em Defesa do SUS, vem priorizar a imprescindível repolitização do SUS como caminho para enfrentar os desafios apontados. Da mesma forma, a diretriz do Pacto pela Vida vem reafirmar o compromisso com a Atenção Básica e com a Saúde da Família como caminhos para a reorganização dos serviços de saúde (BRASIL, 2006a).

A vivência em uma Unidade de Saúde da Família decorrente da inserção no Curso de Residência Multiprofissional em Saúde da Família proporcionou a experiência de trabalho em equipe com profissionais de diferentes categorias da saúde, bem como a participação em instâncias decisórias da comunidade tais como as reuniões locais e municipais dos conselhos de saúde. Essa experiência motivou o estudo sobre as concepções das principais políticas públicas que os diversos atores sociais do SUS daquela realidade possuíam. Para isso, as pesquisadoras elegeram três atores sociais: vereadores, profissionais e conselheiros de saúde para investigar e discutir a compreensão que eles possuíam acerca das potencialidades e dos desafios encontrados para a consolidação do SUS, tampouco da Política Nacional da Atenção Básica (PNAB) e Estratégia da Saúde da Família (ESF).

O presente estudo teve o objetivo de avaliar as percepções de conselheiros municipais de saúde, profissionais da atenção primária e vereadores sobre os conceitos teórico-práticos referentes ao SUS e a PNAB. A partir dessas concepções, pretende-se verificar a participação em projetos e ações que reflitam em discussões sobre os desafios do SUS, bem como analisar as propostas desses atores acerca de melhorias para o sistema.

\section{Material e Método}

Trata-se de um estudo de abordagem qualitativa, descritivo e exploratório com a finalidade de descrever os fenômenos pesquisados por meio da observação, descrição e classificação do objeto de estudo, como também explorar as dimensões desse fenômeno (POLIT, 2004).

O cenário da pesquisa foi o município de Londrina-PR, um dos pioneiros na implantação da Atenção Primária no final da década de 1970, implantando serviços descentralizados e contribuindo para a implementação das políticas de municipalização dos serviços de saúde no estado do Paraná.

Participaram deste estudo três grupos de atores distintos e de extrema importância para a compreensão de seu objetivo. Dentre eles estão conselheiros de saúde, profissionais de saúde da atenção primária e vereadores. A coleta de dados deu-se no período de novembro a dezembro de 2010, após parecer favorável do Comitê de Ética em Pesquisa da Universidade Estadual de Londrina (Pareceres 221/10 - CAAE 0203.0.268.00-10, 226/10 - CAAE 0206.0.268.000-10 e 227/10 CAAE 0207.0.268.000-10) e autorizações do Conselho Municipal de Saúde, da Autarquia Municipal de Saúde e Câmara Municipal de Londrina. 
Participaram deste estudo os conselheiros de saúde representantes dos usuários que estivessem no cargo de titular. No grupo dos profissionais de saúde foi realizada seleção dos trabalhadores de unidades básicas de saúde através de sorteio aleatório, fazendo rodízios pelas regiões do Município (Leste, Oeste, Norte, Sul e Centro). Já o critério de seleção dos vereadores foi a obtenção da participação dos vereadores titulares, com representação dos diferentes partidos políticos por meio de sorteio, sendo a totalidade dos entrevistados dada pela técnica de saturação.

Os entrevistados foram contatados previamente por telefone sendo convidados e orientados sobre o tema da pesquisa, seus objetivos e procedimentos. Mediante a concordância em participar e assinatura do termo de consentimento livre e esclarecido, deuse a coleta de dados, realizada por meio de entrevista semiestruturada. O instrumento de entrevista possuía questões para caracterização pessoal e profissional dos grupos, bem como questões voltadas a verificar o conhecimento destes em relação ao SUS, Atenção Básica e Saúde da Família.

As entrevistas foram gravadas, transcritas em sua forma integral e analisadas por meio da técnica de análise de conteúdo que procura conhecer aquilo que está oculto pelas palavras, de forma a trabalhálas, bem como as suas significações, buscando outras realidades por meio das mensagens. Para isso, são utilizadas técnicas parciais, porém, que se complementam em explicitar e sistematizar os conteúdos das mensagens, com o auxílio de índices passíveis ou não de serem quantificados. Sendo que o analista tem ao seu dispor ou pode criar todo um jogo de operações analíticas, mais ou menos adaptadas à natureza do material e à questão que procura resolver (BARDIN, 2009).

Como critério para identificação de relatos dos diferentes grupos participantes da pesquisa, utilizou-se as letras $\mathrm{P}, \mathrm{C}$ e V, sendo sinalizadas, respectivamente, com " $\mathrm{P}$ " as falas dos Profissionais de Saúde integrantes da ESF, com "C" os conselheiros representantes do seguimento dos usuários e por fim, com "V" os vereadores.

\section{Resultados e Discussão}

\section{Caracterização dos Participantes}

Participaram do estudo 10 profissionais com ensino superior, integrantes de equipes da ESF distribuídas em cinco regiões do município de Londrina; incluindo 03 médicos, 04 enfermeiros e 03 dentistas, que atuam na ESF. Para cada UBS sorteada de uma região, um profissional das categorias citadas era sorteado. Desta forma, foram entrevistados 01 profissional da região norte, 02 da sul, 02 da central, 03 da leste e 02 da região oeste. Quanto à escolaridade dos profissionais; 3 possuem nível superior, 4 especialização em saúde coletiva ou saúde da família, 2 especialização em outras áreas e 1 mestrado.

No grupo amostral referente ao Conselho Municipal de saúde, foram convidados a participar da pesquisa 12 conselheiros titulares do seguimento representante dos usuários, desses, 02 se recusaram a participar. Assim, o estudo contou com a colaboração de 10 conselheiros municipais de saúde. Com relação à escolaridade a maioria dos conselheiros relatou possuir ensino médio, apenas um referiu ter cursado ensino superior. Todos informaram realização, pelo menos uma vez, de curso de capacitação ou palestra para conselheiros.

Durante o período de coleta de dados, a Câmara Municipal de Londrina contava com 19 vereadores e a representação de 09 partidos políticos. Foram selecionados 10 vereadores para a entrevista, sendo que 01 vereador encontrava-se sem partido político por questões administrativas. Houve perda de um dos participantes, pois foram agendadas 04 entrevistas sem a possibilidade de concluí-las. A princípio não houve recusas, porém, no decorrer do estudo, 01 participante mudou sua posição se negando a colaborar com a pesquisa. Atingindo-se 
esta representatividade com a participação de 08 vereadores de 08 distintos partidos políticos. Com relação à escolaridade a maioria cursou ensino superior, sendo três vereadores com pós-graduação e dois com nível médio completo.

\section{Conceito de Saúde}

Para a consolidação da Reforma Sanitária, considera-se importante que atores sociais com tamanha influência no cenário da organização dos serviços de saúde se orientem pelo conceito mais ampliado deste tema, como consta no relatório final da VIII Conferência Nacional de Saúde que diz:

Em seu sentido mais abrangente, a saúde é a resultante das condições de alimentação, habitação, educação, renda, meio ambiente, trabalho, transporte, emprego, lazer, liberdade, acesso e posse da terra e acesso a serviços de saúde. É, assim, antes de tudo, o resultado das formas de organização social da produção, as quais podem gerar grandes desigualdades nos níveis de vida (CONSELHO NACIONAL DE SAÚDE, 1986, p. 4).

Os diferentes grupos abordados fazem alusões à perspectiva complexa da saúde com referências ao equilíbrio entre o bem estar físico e emocional, associado a práticas de esportes e lazer, bom relacionamento familiar, ter uma religião, boas condições de trabalho, moradia, alimentação e estabilidade financeira. Ainda assim, permanece nas falas dos representantes dos usuários no conselho municipal de saúde, a saúde conceituada como ausência de doença e a importância do atendimento médico nas seguintes frases:

Ter saúde é muito amplo gente, ter saúde é você ter o direito de uma boa moradia, ter direito de uma alimentação pra tudo funcionar bem, ter direito a educação por que sem ela você faz coisas que vai trazer danos na saúde física... sabe aquelas coisas de não fumar, não beber e não usar drogas... é daí por diante (V1).

[...] saúde é você estar bem consigo, ter uma boa alimentação, praticar esporte, tudo aquilo que rege a sua vida para você não ter doenças*, fazer uma boa alimentação, ter acompanhamento médico, isso é saúde*(grifo nosso) (C3).

Esses fragmentos evidenciam a necessidade de se ampliar o debate acerca do conceito de saúde para que todos os atores do cenário político possam compreender a sua complexidade e a sua multideterminação. Para isso se faz necessário que conselheiros, vereadores e profissionais se apropriem de conhecimentos acerca desse tema para que possa haver a mudança no modelo e nas práticas de cuidado em saúde. O movimento sanitário foi uma resposta às crises de conhecimentos e de modelo biomédico, das condições sanitárias da população e do sistema de prestação de serviços à saúde em que o país se encontrava. Foi a partir dessas condições problemáticas que o governo propôs ampliar os debates acerca do processo saúde-doença (FLEURY, 2009).

\section{Utilização dos Serviços de saúde}

No que se refere à utilização dos serviços de saúde, a maioria dos entrevistados informa adesão a planos de saúde suplementares. O grupo dos profissionais de saúde relata que usualmente em caso de doença se autoavaliam e realizam autocuidados, recorrendo a outros profissionais somente em casos mais graves e específicos.

Entretanto, com exceção do mencionado grupo, unânime em informar que o atendimento na saúde pública é bom, os conselheiros e vereadores demonstram ressalvas quanto à qualidade da atenção prestada pelo SUS.

Olha dessa vez, infelizmente eu tive que procurar SUS* porque quando menos esperava eles tinham descoberto a parte cardíaca minha e como é que eu ia sair do hospital? Daí apesar de titular eu não tinha cobertura do plano, que tinha que ser particular, pagar tudo. [...] Mas eu sempre aconselho as pessoas a procurar o SUS porque a saúde é direito 
de todos cidadãos independente de classe e de cor, é dever do Estado, isso eu falo direto para as pessoas (Grifo nosso) (C5).

Vale lembrar que esta temática não teve início recente, em trabalho realizado por Telles (1994), observa-se por exemplo, a deterioração dos sistemas públicos, inclusive de saúde, impulsionada pela falência de políticas sociais e acentuada com a tendência de mercado que incentiva a adesão a sistemas privados de saúde.

Essa procura por convênios privados evidencia grande preocupação com a doença, parece não considerar os determinantes do processo saúde/ doença e nem as ações de promoção da saúde, conforme os princípios e diretrizes do SUS, além de reforçar o modelo hegemônico de assistência à saúde pautada na consulta médica individual (KRUGER, 2000).

Ainda sobre o atendimento nos serviços públicos de saúde, relataram que existe diferença no atendimento como facilitações para o acesso de determinadas pessoas, ainda que involuntariamente por parte das instituições, demonstrado em:

Olha, como eu sou uma pessoa pública, o atendimento é diferenciado (V6).

[...] porque na verdade é diferente quando você é médico ou até qualquer outro profissional de saúde quando você é atendido pelo SUS, então o tratamento acaba sendo, talvez involuntariamente pelo profissional, mas você é um pouquinho mais bem atendido (P1).

A análise da categoria dos conselheiros evidenciou ainda que os integrantes deste grupo, dependentes exclusivamente do SUS, são dotados de maior conhecimento acerca do funcionamento dos serviços e das políticas de saúde, portanto os que mais exigem o cumprimento dos direitos dos usuários com argumentos conceituais e realistas. Agregando, ainda, a temática do controle social como mecanismo de conquista de melhorias ao serviço de saúde.
Não tenho plano privado, não era pra nenhuma pessoa ter. Meus filhos, meus netos às vezes reclamam, eu falo não senhora a gente tem que lutar para que o SUS dê certo, eu não tenho condições de pagar por um plano, mas mesmo se eu tivesse eu não ia ter plano de saúde não $(\mathrm{C} 1)$.

A primeira coisa que penso é em procurar a minha unidade básica mesmo, é na unidade básica que eu vou lá buscar as informações e é lá que faz os encaminhamentos pra outras instituições (C2).

A sociedade precisa se agrupar e ajudar mais, cobrar a melhoria como um todo e parar de cobrar a coisa individual pra si mesmo, porque a visão maior dessa sociedade é se eu resolvi meu problema acabou não vou atrás de resolver o dos outros (C3).

Vivenciar a unidade como referência fortalece a relação com a rede e assim demonstra empoderamento conceitual para sua participação mediante as deliberações do conselho, considerando que a participação dos conselheiros nas questões que envolvem o serviço de saúde pública, tange a formulação de estratégias, monitoramento da execução da política pública de saúde, bem como questões financeiras.

\section{Conceito de SUS}

Produto da reforma sanitária, o SUS é um arranjo organizacional do Estado brasileiro que busca a consolidação da política de saúde por meio de seus princípios e diretrizes que são a universalidade, integralidade, equidade, o direito a informação, a descentralização, hierarquização, participação comunitária e a integração (VASCONCELOS; PASCHE, 2006).

Apresentou-se evidente o desconhecimento dos princípios e diretrizes do SUS, a dificuldade em exemplificar com situações cotidianas e relatos não conceituais a definição do sistema, principalmente nos grupos dos conselheiros e vereadores. Outrossim, foi tratada repetidamente a dicotomia entre o aparato legislativo e conceitual em relação ao serviço prestado.

Principio... SUS... então que me deram curso, assim... capacitação. SUS é um sistema de saúde que abrange todos os problemas de saúde e para todas 
as classes independente tipo assim é... de credo, de cor, nacionalidade. Mas já ouvi falar esses dias de pessoas entendidas que o SUS ta capengando (C5).

[...] palavras básicas que estão no papel? O conceito do SUS é aquela babaquice de integridade e blábláblá. Que todo mundo ta careca de saber. Mas funciona no papel e na pratica não funciona, que fala em equidade... (C3).

Eu conheço sobre o SUS o que a gente vê no dia a dia e no sofrimento do cidadão que a gente recebe. Ele é um sistema bonito, foi criado, eu não vou te dar detalhes porque não me lembro (V6).

A falta de conhecimento sobre as políticas de saúde pode levar à defesa de um modelo de saúde excludente, mercantilista, biologicista e médicocentrado além da crença de que seja um serviço direcionado às populações mais carentes, ou seja, um retrocesso às conquistas da reforma sanitária. Ainda que conceituada com equívocos ou apenas com conteúdo de senso comum, fica claro que são percebidas limitações nos serviços de saúde pública. Entretanto, as proposições para mudança do quadro permanecem confusas e com conotações distorcidas.

O atendimento de saúde pra população mais carente que nós temos hoje é precário em um monte de lugar, roubam descaradamente muito dinheiro, mas mesmo assim é vitorioso o resultado do SUS, porque permite uma política pública permanente ao cidadão que mais precisa (V2).

A minha proposta seria aumentar o número de médicos e melhor pagamento dos médicos (V1).

Então seria voltar ao que era antigamente que você era bem atendido há uns 15 anos atrás, em 92, 93, por exemplo, até meados de 2000 e lá vai cacetadas aí... tudo era bem controlado, o negócio funcionava porque eu era atendido pelo INPS* (Grifo nosso) (C8).

Esta última fala traz como proposta de melhoria do sistema de saúde, revisitar o atendimento prestado entre o início da década de 90 até meados de 2000. No entanto, a referida época trata-se do SUS, visto que a assistência médica prestada pelo INPS (Instituto Nacional de Previdência Social) era restrita e em 1978 passou a ser responsabilidade do Instituto Nacional de Assistência Médica da
Previdência Social (INAMPS), que por sua vez foi extinto em 1993 (COHN; ELIAS, 2005)

$\mathrm{Na}$ categoria dos profissionais de saúde, ficou caracterizado maior conhecimento sobre a abrangência teórico-prática referente ao SUS. Entretanto, em geral, considera-se um sistema em construção e com uma teoria de excelente qualidade. $\mathrm{Na}$ prática foram apontadas várias dificuldades e obstáculos que não garantem a efetividade do sistema.

É o melhor programa de saúde que existe, do planeta Terra, sim! Mas também na teoria. Porque aqui no Brasil se têm grandes ideias, grandes programas, mas na prática tem que viabilizar esses programas e não se consegue (P7).

Com princípios doutrinários e organizativos de alta qualidade, o SUS requer permanentes propostas de estratégias para a consolidação no seu campo de ação (MARTINS et al., 2009). Em consonância ao pautado pelos grupos, para Santos (2004) o ideário e a legislação pertinente ao SUS permanecem atuais e legítimos, enquanto a revisão de suas estratégias de implementação apresenta-se inadiável.

Essa visão se remete aos objetivos da publicação do Pacto pela Saúde, que visa concretizar operacionalmente o SUS, qualificar e implementar o processo de descentralização, organização e gestão do sistema de saúde do Brasil com aprimoramento de pactuação intergestores (FADEL et al., 2009).

Para garantir a saúde como direito social, com acesso e utilização dos serviços, para toda população brasileira, o SUS precisa de financiamento suficiente e sustentável, contando com a responsabilidade e compromisso das três esferas de governo em zelar pela qualidade dos gastos, não gerando desperdícios (DAIN, 2007).

Alguns entrevistados relacionaram falhas no funcionamento do SUS com a questão do 
financiamento. Estes acham que, apesar de existir um subfinanciamento para o setor saúde, os gastos são mal direcionados, mal planejados, consequentemente, o sistema se torna ineficaz e ineficiente.

A importância da participação da comunidade no controle do SUS é compreendida quando observa-se o modo de construção e execução de políticas públicas de saúde no Brasil, em que alguns gestores ainda fazem da máquina pública um meio de atender a interesses de grupos e indivíduos particulares em detrimento aos direitos dos cidadãos (SCHNEIDER et al., 2009).

\section{Politica Nacional da Atenção Básica (PNAB)}

A PNAB, instituída pela portaria $n^{\circ} 648 / \mathrm{GM}$ de março de 2006, estabelece diretrizes e normas para a organização da Atenção Básica, para a ESF e Programa de Agentes Comunitários de Saúde (PACS) (BRASIL, 2006b).

Esta política ampliou o escopo da atenção básica e reafirmou a Saúde da Família como estratégia prioritária e modelo substitutivo para organização da atenção básica (GIOVANELLA, 2009). Documentos como este deveriam orientar os atores envolvidos com a saúde pública brasileira, para a construção de novos e qualificados rumos de implementação e consolidação do SUS (BRASIL, 2006b). Entretanto, os entrevistados não conhecem ou apenas ouviram falar sobre a política.

Atenção básica... não conheço muita coisa não, vou ser sincera em dizer... eu acho que aqui na nossa região não é aplicada ainda, então não tenho muito conhecimento sobre isso não... meu negócio é brigar mais pelas construções do que por essa parte [...] (C3).

Assim, por mais que a mudança do modelo venha a propor uma organização do sistema a fim de promover saúde, a influência das práticas tradicionais é muito forte. Até quando das falas emerge a valorização da atenção básica, advém de uma visão minimalista e com priorização da qualidade do serviço hospitalar (COSTA, 2009). Este tipo de posicionamento dificulta a consolidação da proposta ampliada de atenção à saúde, com vínculo serviço-comunidade, principalmente quando esta opinião é associada a pessoas em posições como membros do conselho de saúde, profissionais da atenção primária e vereadores.

Eu acho que mudou muito nesses últimos tempos, pelo próprio programa de saúde da família, onde tem um atendimento mais localizado [...] acho que nós temos que melhorar em termo de socorrer as estruturas maiores dos hospitais grandes que nós temos aqui"(V3).

[...] você tendo uma equipe multiprofissional, multidisciplinar $[\ldots]$ às vezes evita muito uma consulta médica, como no caso de hoje, que é o mais limitado no SUS é o número de consultas médicas. Então, daria para voltar um pouco mais para a prevenção, com a contratação mesmo de outros funcionários, ou outros profissionais (P1).

O município de Londrina foi pioneiro na implantação da atenção básica, ainda no final da década de 70 , por conseguinte esta temática deve estar em evidência entre os representados grupos desde então. Embora a PNAB tenha sido publicada em 2006, a discussão de mudança de paradigma não é atual. É compreensível que os grupos demonstrem distância quanto às múltiplas disposições e particularidades da política em si. Entretanto, percebe-se com estranheza que tão relevantes atores compreendam seus preceitos básicos de forma distorcida.

\section{Saúde da Família}

Para organização da atenção básica a PNAB apresenta a Estratégia Saúde da Família como modelo prioritário e substitutivo à Atenção Básica tradicional, de acordo com os preceitos do SUS. A ESF atua moldando suas ações a partir do cadastramento familiar, diagnóstico situacional do território, atendimento aos principais problemas de 
saúde da comunidade; manutenção do cuidado das famílias ao longo do tempo; buscando integração com instituições e organizações sociais da área de abrangência e sendo espaço de construção da cidadania (BRASIL, 2006b).

Nesta questão, os profissionais de saúde, em geral, foram mais claros ao apresentar as definições teórico-práticas na temática da saúde da família. Em todas as categorias encontrou-se unanimidade em afirmar a importância da estratégia para a qualidade do cuidado à saúde. Entretanto, apresentam-se em destaque, os equívocos ao descrevê-la:

Então, a informação que a gente tem de pessoas que a gente conhece, é uma satisfação enorme da população de ser respeitada como cidadão, ter o atendimento adequado, devido e sabendo que não está usando o hospital, não está ocupando leito. (V8)

O saúde da família acaba sendo atendimento domiciliar e isso poderia mudar, porque o que acaba acontecendo é que o horário para o saúde da família é muito pouco, é muito curto, então acaba tendo poucas vagas para você tentar fazer um atendimento ou tentar fazer uma visita domiciliar ou tentar fazer um projeto $(\mathrm{P} 1)$

Bom, conheço esta questão do atendimento, o trabalhos dos ACSs, (agentes comunitários de saúde) o trabalho da equipe médica, das visitas e o trabalho com os acamados (P5).

Fica evidente nas falas, a percepção reduzida da ESF como a realização de visitas regulares apenas às pessoas impossibilitadas de se deslocar até a unidade de saúde. Dentro deste contexto, até mesmo alguns profissionais de saúde não conseguem associar o trabalho realizado dentro da unidade de saúde à ESF.

\section{Ações para Fortalecimento do SUS}

Embora se observa relevante déficit quanto à apropriação dos temas trabalhados neste estudo pelos grupos entrevistados, foram apresentadas diversas hipóteses acerca das falhas em relação a consolidação dos serviços de saúde do município. Foram levantadas problemáticas como: falta de profissionais, estrutura física precária, gestão inadequada, repasse financeiro insuficiente.

Os conselheiros de saúde, em sua maior parte, demonstram desinteresse em se apropriarem dos conteúdos teóricos acerca dos marcos legais e orientadores do SUS, ainda assim, destaca-se em suas falas a carência de capacitações sobre as temáticas discutidas.

\begin{abstract}
Nossa eu sou um relaxo sabe por quê? Eu detesto ficar lendo livros, essas coisas. Eu conheço esse projeto do governo de saúde no sentido de atender a todos igualmente, em todos os cantos. Princípios e diretrizes não sei... De repente eu até sei, falo deles e até vivo, mas não sei te dizer: isso é uma diretriz (C7).
\end{abstract}

Nenhum dos profissionais entrevistados participa de projetos voltados à discussão e consolidação do SUS e/ou reuniões de conselho local de saúde.

\begin{abstract}
Não falta convite, o pessoal até chama a atenção: se você quer mudar, se não está satisfeito com a situação, você tem que tentar mudar, mas você, efetivamente, participando, se dedicando. E eu sou sincero, a gente acaba se acomodando na nossa própria rotina. Então, eu não estou tendo oportunidade de participar (P8).
\end{abstract}

Ficou evidenciado nas falas dos atores acima certa passividade para o envolvimento nas ações de fortalecimento do SUS. Houve um descaso com relação ao domínio dos referenciais teóricos, bem como uma falta de engajamento nos espaços dedicados a discussão e a proposição de projetos para o SUS. Essa constatação remete a reflexão sobre construção política dos sujeitos e falta a noção de que pertença aos processos decisórios das políticas. (FLEURY, 2009)

Quando questionado aos vereadores quanto a criação de projetos voltados para a saúde, apenas um, que a propósito, está em seu quinto mandato, informa já ter feito projetos que considera voltado para a saúde, citando-os: 
Eu tenho um projeto aprovado aí há uns 4, 5 anos... a questão da obesidade infantil. Nessa época que o projeto tornou-se lei e encaminhamos para as escolas [...] no sentido de que a escola pudesse fazer campanha, para que melhorassem o cardápio [...] e também para orientação das famílias... (V8).

"Aí eu fiz uma lei também, exigindo que os restaurantes, mais as lanchonetes e serviços que fornecem lanche, fossem obrigados a ter saches, pelo menos é mais higiênico e mais saudável" (V8).

Os projetos voltados para futuras melhorias, muitas vezes, dão-se distante do contexto de maior necessidade local e não abrangem o conceito ampliado de saúde vigente na Constituição Federal. De acordo com Kruger (2000), a maioria dos documentos oficiais prioriza o âmbito social e, considera que a carência de efetivação de muitas destas políticas deve-se à falta de estratégia de planejamento.

\section{Conclusão}

A presente pesquisa teve o intuito de identificar o conhecimento sobre SUS e a PNAB de três diferentes sujeitos: conselheiros de saúde (usuários), profissionais de saúde (trabalhadores) e vereadores (gestores), selecionados pela importância que possuem como formadores de opinião, no qual estes atores, com seus saberes e interesses, possuem potencial para buscar uma nova forma de organizar os serviços de saúde, rumo ao desenvolvimento do SUS.

Os conselheiros de saúde, de forma geral, não conseguiram falar sobre o SUS e a Política da Atenção Básica de forma clara. Muitos conceitos apresentados foram através de opiniões pessoais e por conta disso não conseguiram aprofundar nas discussões sobre a saúde de forma geral e sobre os problemas enfrentados pela atenção básica.

Os profissionais de saúde entrevistados mostraram conhecimentos teóricos em relação ao SUS, Atenção Básica e Saúde da Família, apesar de não se familiarizarem com a publicação da Política Nacional da Atenção Básica e acreditarem que, documentos como este, não são interessantes para leitura, pois a teoria não é, muitas vezes, viabilizada na prática. Prática essa dificultada pela precarização da política de recursos humanos em saúde.

Observou-se que o significado de saúde, para os vereadores, quando se pensa o individual, é bastante abrangente incorporando os determinantes sociais para qualidade de vida, entretanto, no sentido coletivo, o mesmo não acontece. Indicam como primordial investimentos em saúde pública, uma vez que reconhecem o estado frágil do setor. Contudo, demonstram conhecimento superficial e equivocado sobre os conceitos de SUS, Atenção Básica, Saúde da Família e não reconhecem a PNAB. Destaca-se em suas colocações, valorização do modelo hospitalocêntrico, atendimento de livre demanda e médico-centrado.

Observa-se, também, desarticulação entre o legislativo, serviços de saúde e controle social. Em suas falas, os grupos reconhecem que a saúde pública, de modo geral, encontra-se em um contexto delicado e apontam o que entendem como fatores causais desta situação, que repetidas vezes, chamaram de caótica. No entanto, não possuem projetos que visem mudança deste cenário e seus posicionamentos não se demonstram em defesa do SUS.

É preciso que os sujeitos se apropriem de conhecimento teórico sobre as políticas que envolvem a organização da saúde pública para que sejam mudados os paradigmas do modelo tradicional e a atenção básica seja valorizada e compreendida como forma de organização do sistema. A proximidade e vínculo entre os atores pesquisados colocariam a atenção básica e a saúde da família em um patamar estratégico para diálogos e construção de sujeitos sociais e políticos, com interesses e saberes diferentes em busca do direito real de saúde. 


\section{Referências}

BARDIN, L. Análise de conteúdo. Lisboa: Ed. 70, 2009.

BRASIL. Ministério da Saúde. Diretrizes operacionais dos pactos pela vida, em defesa do SUS e de gestão. Brasília, 2006.

. Ministério da Saúde. Secretaria de Atenção à Saúde. Politica nacional de atenção básica. Brasília, 2006.

COHN, A.; ELIAS, P. Saúde no Brasil: políticas e organização de serviços. 6. ed. São Paulo: Cortez, 2005.

CONSELHO NACIONAL DE SAÚDE. Relatório final da $8^{a}$ Conferência Nacional de Saúde. Brasília, 1986.

COSTA, G. D.; COTTA, R. M. M.; FERREIRA, M. L. S. M.; REIS, J. R., FRANCESCHINI, S. C. C. Saúde da família: desafios no processo de reorientação do modelo assistencial. Revista Brasileira de Enfermagem, Brasília, v. 62, n. 1, p. 113-118, 2009.

DAIN, S. Os vários mundos do financiamento da saúde no Brasil: uma tentativa de integração. Ciência e Saúde Coletiva, Rio de Janeiro, v. 12, sup., p. 1851-1864, 2007.

ESCOREL, S. Reviravolta na saúde: origem e articulação do movimento sanitário. Rio de Janeiro: Fiocruz, 1998.

FADEL, C. B.; SCHNEIDER, L.; MOIMAZ, S. A. S.; SALIBA, N. A. Administração pública: o pacto pela saúde como uma nova estratégia de racionalização das ações e serviços em saúde no Brasil. Revista de Administração Pública, Rio de Janeiro, v. 43, n. 2, p. 445-456, 2009.

FLEURY, S. Reforma sanitária brasileira: dilemas entre o instituinte e o instituído. Ciência e Saúde Coletiva, Rio de Janeiro, v. 14, n. 3, p. 743-52, maio/jun. 2009.

GIL, C. R. R. Práticas profissionais em saúde da família: expressões de um cotidiano em construção. Tese (Doutorado em Saúde Pública) - Escola Nacional de Saúde Pública, Rio de Janeiro, 2006.
GIOVANELLA, L.; MENDONÇA, M. H. M.; ALMEIDA, P. F.; ESCOREL, S.; SENNA, M. C. M.; FAUSTO, M. C. R.; DELGADO, M. M.; ANDRADE, C. L. T.; CUNHA, M. S.; MARTINS, M. I. C.; TEIXEIRA, C. P. Saúde da família: limites e possibilidades para uma abordagem integral de atenção primária à saúde no Brasil. Ciência e Saúde Coletiva, Rio de janeiro, v. 14, n. 3, p. 783-794, 2009.

GUEDES, A. E. L. Da integração de programas à integralidade de ações de saúde: algumas reflexões preliminares. In: PINHEIRO, R., MATTOS, R. A. Os sentidos da integralidade na atenção e no cuidado à saúde. Rio de Janeiro: Abrasco, 2001. p. 127-156.

KRÜGER, T. R. A construção do SUS: o reconhecimento dos seus limites na fala de conselheiros. Linhas, Florianópolis, v. 1, n. 1, 2000a. Disponível em: <http://www.periodicos.udesc. br/index.php/linhas/article/viewFile/1314/1125>. Acesso em: 6 fev. 2011.

. O desconhecimento da reforma sanitária e da legislação do SUS na prática do conselho de saúde. Planejamento e Políticas Públicas, Brasília, n. 22, p. 119-144, 2000b. Disponível em: <https://www.ipea. gov.br/ppp/index.php/PPP/article/viewFile/82/162>. Acesso em: 12 jan. 2011.

LEVCOVITZ, E.; LIMA, L. D.; MACHADO, C. V. Políticas de saúde nos anos 90: relações intergovernamentais e o papel das normas operacionais básicas. Ciência e Saúde Coletiva, Rio de Janeiro, v. 6, n. 2, p. 269-291, 2001.

MARTINS, R. J.; MOIMAZ, S. A. S.; GARBIN, C. A. S.; GARBIN, A. J. I.; LIMA, D. C. Percepção dos coordenadores de saúde bucal e cirurgiões-dentistas do serviço público sobre o sistema único de saúde (SUS). Saúde e sociedade, São Paulo, v. 18, n. 1, p. 75-82, 2009.

NEGRI, B.; VIANA, A. L. A. (Org.). O Sistema único de saúde em dez anos de desafio: o passo a passo de uma reforma que alarga o desenvolvimento e estreita a desigualdade social. São Paulo: Sobravime, 2002.

POLIT, D. F.; HUNGLER, B. P. Fundamentos da pesquisa em enfermagem. 4. ed. Porto Alegre: Artes Médicas, 2004. 
SANTOS, N. R. Organização da atenção à saúde: é necessário reformular as estratégias nacionais de construção do "modelo SUS"? Saúde em Debate, Londrina, v. 28, n. 68, p. 279-288, 2004.

SCHNEIDER, A.; PERALTA, J. A. G.; BOTH, V.; BRUTSCHER, V. Pacto pela saúde: possibilidade ou realidade. 2. ed. Passo Fundo: IFIBE; 2009.

TELLES, V. Sociedade civil e os caminhos (incertos) da cidadania. São Paulo em Perspectiva, São Paulo, n. 8, p. 7-14, 1994.

VASCONCELOS, C. M.; PASCHE, D. F. O Sistema Único de Saúde. In: CAMPOS, G. W. S.; MINAYO, M. C. S.; AKERMAN, M.; DRUMOND JUNIOR, M.; CARVALHO, Y. M. (Org.). Tratado de saúde coletiva. São Paulo: Hucitec, 2006. 